\title{
Serum Biomarkers of Environmental Enteric Dysfunction and Growth Perspective in Egyptian Children
}

\author{
Maged A. El Wakeel ${ }^{1}$ D, Ghada M. El-Kassas ${ }^{1} \mathbb{D}$, Shaimaa A. Hashem ${ }^{1}$ D, Hasanin M. Hasanin ${ }^{2}$, Walaa H. Ali ${ }^{1 *}$ (D) \\ Alshaimaa A. Elkhatib, Hiba Sibaii ${ }^{3}$ DNevein N. Fadl ${ }^{3}$ \\ ${ }^{1}$ Department of Child Health, National Research Centre, Giza, Egypt; ${ }^{2}$ Department of Pediatrics, National Research Centre, \\ Giza, Egypt ; ${ }^{3}$ Department of Medical Physiology, National Research Centre, Giza, Egypt
}

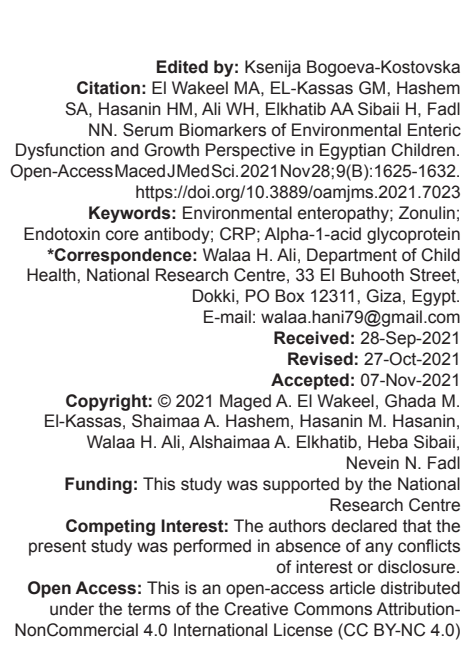

\section{Introduction}

Environmental enteric dysfunction (EED) is impending trouble that flared up in the past decades to be pervasive in infants and children. EED is a subclinical condition linked to poverty and bad hygiene. It is a burden and highly attributed to low- and middle-income countries [1]. It is strongly associated with stunting with high affection of height more than weight for age.

It was previously mistaken with other diseases such as tropical sprue, celiac disease, and inflammatory bowel disease (ulcerative colitis and Crohn's disease) [2]. Initially, it was known as tropical enteropathy but later on, it has renamed into "environmental enteropathy" as it is not limited to tropical areas. Recently, it is further renamed as "environmental enteric dysfunction" [3], [4], [5].

Many researches handled the pathogenesis and mechanisms involved in EED. The histopathology emphasis that it is a disease of small bowel that involves flattened short villi with deep crypts, and lymphocytic infiltration, this structural change may lead to functional disturbances and decreased surface area for nutrient absorption and consequent malnutrition [6]. The underlying mechanism of pathology is interacting play between five main aspects: Intestinal inflammation, damage, repair, microbial translocation, permeability and absorption, and systemic inflammation [7].

A constellation of consequential events initiated by disruption of the gut integrity, with breakdown of cellular tight junctions, leading to fenestrated permeable wall allowing bacterial translocation into the systemic circulation. This leads to activation of the immune system and acute-phase reactant release, with subsequent inhibition of insulin-like growth factor-1 resulting in linear growth suppression [8].

In addition, loss of the absorptive function of the short blunted intestinal villi leads to defect in absorption of essential macro- and micro-nutrients affecting growth [9].

EED has been inclined with great health affection; it is highly associated with faltering growth mainly stunting in childhood which is highly associated 
with adulthood non-infectious diseases (hyperlipidemia, hypertension, insulin resistance, obesity, cardiovascular diseases, and diabetes mellitus [DM]) [10], [11].

There is evident link and relation between early stunting growth at early infant life and later consequence of impaired health, poor cognitive function, intellectual performance, and academic achievement [12], [13].

The criteria for diagnosis of EED have not been established yet. The golden diagnostic confirmatory method of EED is endoscopy and small intestinal biopsy which is considered as invasive, cost, and need technical experience, therefore, it is usually avoided measure [14]. Consequently, researches are challenging the usage of less invasive available biomarkers that emerged from the underlying mechanism of EED pathology to help in diagnosis.

Fecal and serum biomarkers of inflammation are available. However, no single biomarker or group of biomarkers has been thoroughly validated or documented to capture EED [7].

Highly sensitive C-reactive protein (hsCRP) and alpha-1-acid glycoprotein (AGP) and tumor necrosis factor (TNF) belong to acute-phase proteins family that produced from the liver in response of infectious inflammation and other non-infectious inflammatory states. These biomarkers are considered as systemic markers of intestinal inflammation [1], [15].

The antibody of endotoxin core is a marker of microbial translocation. It is produced by $B$ cells in response to repeated bacterial enteric infections. It measures antibodies against endotoxin lipopolysaccharide (LPS) of Gram-negative bacteria that have translocated across a leaky gut [2], [5], [7].

Zonulin is a human analog of zonula occludens toxin which is known to affect tight junctions between enterocytes, it causes an intracellular signaling cascade that results in opening of tight junctions, and its elevation indicates increased intestinal permeability [2], [5], [16].

There is rising need to search for validated and approved biomarkers that can help in diagnosis and predict implications of EED as well as to evaluate management and enhance the prognosis.

The objectives of the study were to measure a group of potential available serum biomarkers involved in EED and determine their association with stunting and faltering growth in children.

\section{Subjects and Methods}

This is a case-control study conducted in 2020. It has randomly enrolled 105 children with moderate malnutrition, having weight-for-age z-scores and height-for-age z-scores (WAZ or HAZ) ranging from -1.5 to -2 . They were of both sexes, aged from 1 to 10 years old, attending child health Clinic in Medical and Scientific Centre of Excellence, National Research Center (NRC), Cairo, Egypt. One hundred healthy children of matched age and sex, having WAZ and HAZ $>-1$ were enrolled in the study as controls.

\section{Exclusion criteria}

Children with chronic debilitating illness including (congenital heart diseases, chronic renal problems, and neurological or developmental disabilities), congenital abnormalities or genetic disorders, recent history or present case of diarrhea or hematochezia, and heavy parasitic infestation at time of inclusion (was excluded by stool analysis).

This study is a part of the in-house project funded by NRC and approved by the Medical Ethical Committee of the NRC (19/227). All participants were informed about the objectives of the study and ready to participate with obtaining a written informed consent from the parents.

All of them were subjected to; full history taking laying stress on personal data involving date of birth, sex, familial history of short stature or wasting, chronic illness such as DM, HTN, drug intake, and dietary history.

For all children participated in the study, complete clinical examination was done laying stress on signs of vitamins deficiency and anemia and local systemic examination of all body organs. All anthropometric measurements were taken according to techniques described in the Anthropometric Standardization Reference Manual [17]. Weight was measured using a calibrated Seca scale to the nearest $0.1 \mathrm{~kg}$ (Seca, Hamburg, Germany), height was measured using Seca 225 stadiometer to the nearest $0.1 \mathrm{~cm}$ [18]. Mid-arm circumference was measured using flexible graduated tape at the left upper arm in point midway between the tip of humorous and the tip of elbow. Height and weight, BMI were applied to AnthroPlus Pediatric calculator for personal computers to calculate Z-scores for many somatic parameters [19].

The children were defined as malnourished when they were underweight (WAZ) score $<-2$ or stunted growth (HAZ) score $<-2$ or wasted $(\mathrm{WHZ})$ score $<-2$ and as nourished when the WAZ/HAZ/WHZ score was $\geq-2$ based on the WHO standard [20].

\section{Laboratory investigations}

Three milliliters of fasting $(8 \mathrm{~h})$ venous blood samples will be withdrawn from each child. The venous sample was collected in a Vacutainer blood collection tube. The samples were divided into two parts: The first part was added to tube containing ethylenediaminetetraacetic acid for complete blood 
count. The second part put in a serum separator tube and then centrifuged for $10 \mathrm{~min}$ at $3000 \mathrm{rpm}$ to separate the serum from the remaining components. Serum was preserved in sterile Eppendorf tubes and stored in $-80^{\circ} \mathrm{C}$.

Serum iron was quantified using the colorimetric $\mathrm{CAB}$ method. Kit was obtained from Egyptian Company for Biotechnology (S.A.E) Obour City industrial area, block 20008, Cairo, Egypt.

Serum zonulin, endotoxin core antibody (EndoCAb), hsCRP, AGP, and TNF were quantified in serum by an ELISA method using kits purchased from (SunLong Biotech Co., LTD). Zonulin kit detection range was $30-1500 \mathrm{pg} / \mathrm{ml}$ catalog number: SL2712Hu. The EndoCAb kit detection range was 3-120 pg/ml catalog number: SL3521Hu. The AGP kit detection range was 1-80 ng/ml catalog number: SL1845Hu. The TNF kit detection range was $20-400 \mathrm{ng} / \mathrm{L}$ catalog number: SL1761Hu.

Serum Vitamin A and Vitamin D were measured by ELISA technique using commercially available ELISA kits (SunLong Biotech Co., LTD). Vitamin A kit detection range was $50-1800 \mathrm{ng} / \mathrm{ml}$ catalog number: SL1826Hu. Vitamin D kit detection range was $0.8-50 \mathrm{ng} / \mathrm{ml}$ catalog number: SL1831Hu.

\section{Statistical analysis}

Data were collected, verified, coded, and analyzed using the Statistical Package for the Social Sciences (SPSS) version 23 (SSPS Inc., Pennsylvania, USA). Descriptive statistics were used to summarize baseline characteristics of the study population. Frequencies were reported for categorical variables while the mean \pm standard deviation (SD) or standard error for continuous variables. Independent t-test was used to compare between two groups regarding quantitative data, respectively. Pearson correlation analysis was used to assess the relation between two quantitative parameters in the same group. Logistic regression was done to determine factors mostly affecting weight $Z$ score and height $Z$ score among cases using backward Wald. The $p$-values were two tailed, it was considered statistically significant at $p \leq 0.05$ and highly significant at $p \leq 0.001$.

\section{Results}

This case-control study enrolled 105 children as cases compared with 100 healthy age- and sexmatched children as controls, as no significant difference between the two groups ( $p>0.05$ ) (Table 1).

There was a highly significant decrease in cases group $(p<0.001)$ as regarding the anthropometric
Table 1: Comparison between cases and controls groups regarding to age, sex, and anthropometric measurements

\begin{tabular}{llll}
\hline Variable & Cases, $\mathrm{n}=105$ Mean \pm SD & Control, $\mathrm{n}=100$ Mean \pm SD & $\mathrm{p}$-value \\
\hline $\begin{array}{l}\text { Age (months) } \\
\text { Sex }(\mathrm{n} \%)\end{array}$ & $79.71 \pm 34.3$ & $79.33 \pm 39.5$ & 0.85 \\
$\quad$ & & \\
$\quad$ Male & $47(44.8 \%)$ & $46(46.0 \%)$ & 0.859 \\
$\quad$ Female & $58(55.2 \%)$ & $54(54.0 \%)$ & \\
Weight $(\mathrm{kg})$ & $17.88 \pm 5.7$ & $25.18 \pm 11.0$ & $<0.001^{\text {** }}$ \\
Weight Z score & $-2.08 \pm 0.8$ & $0.4 \pm 0.4$ & $<0.001^{\text {** }}$ \\
Height $(\mathrm{cm})$ & $107.94 \pm 15.9$ & $119.91 \pm 21.3$ & $<0.001^{\text {** }}$ \\
Height Z score & $-2.18 \pm 0.8$ & $0.44 \pm 0.4$ & $<0.001^{\text {** }}$ \\
BMI & $15.14 \pm 1.5$ & $16.71 \pm 1.5$ & $<0.001^{\text {** }}$ \\
BMI Z score & $-0.74 \pm 1.2$ & $0.34 \pm 0.4$ & $<0.001^{\text {** }}$ \\
Arm & $16.56 \pm 1.8$ & $17.73 \pm 2.0$ & $<0.001^{\text {** }}$ \\
circumference & & & \\
(cm) & &
\end{tabular}

measurements; weight, height, BMI, and arm circumference (Table 1).

Assessment of serum biomarkers of enteric dysfunction in EED showed significant increase in serum zonulin (biomarker of enteric permeability) and EndoCAb (biomarker of microbial translocation) in cases group as compared to control group ( $p \leq 0.05$ ). Meanwhile, there was significant increase in systemic inflammatory markers of hsCRP and AGP in cases group as compared to controls group $(p \leq 0.05)$. On the other hand, there was a highly significant decrease of serum Vitamin $D$ and iron in cases group as compared to control group ( $p \leq 0.001$ ), while serum Vitamin $A$ and $\mathrm{Hb}$ showed no significant difference between the two groups $(p>0.05)$ (Table 2).

Table 2: Comparison between cases and controls regarding to laboratory results

\begin{tabular}{lllc}
\hline Variable & Cases, $\mathrm{n}=105$ Mean \pm SE & Control, $\mathrm{n}=100$ Mean \pm SE & $\mathrm{p}$-value \\
\hline $\mathrm{Hb}$ & $10.9 \pm 0.8$ & $11.2 \pm 0.9$ & 0.4 \\
Iron & $78.24 \pm 3.1$ & $104.78 \pm 5.4$ & $<0.001^{* *}$ \\
Vitamin $\mathrm{A}(\mathrm{Pg} / \mathrm{ml})$ & $63.26 \pm 2.2$ & $68.02 \pm 3.3$ & 0.884 \\
Vitamin D $(\mathrm{Pg} / \mathrm{ml})$ & $10.19 \pm 0.9$ & $13.5 \pm 0.6$ & $<0.001^{* *}$ \\
$\mathrm{hsCRP}(\mathrm{mg} / \mathrm{L})$ & $4.73 \pm 0.4$ & $1.61 \pm 0.2$ & $0.031^{*}$ \\
$\mathrm{AGP}(\mathrm{mg} / \mathrm{dl})$ & $17.11 \pm 1.4$ & $12.48 \pm 0.9$ & $0.024^{*}$ \\
$\mathrm{TNF}(\mathrm{ng} / \mathrm{L})$ & $44.45 \pm 2.6$ & $39.2 \pm 2.2$ & 0.567 \\
Zonulin $(\mathrm{pg} / \mathrm{ml})$ & $619.3 \pm 15.4$ & $463.2 \pm 12.2$ & $0.02^{*}$ \\
EndoCAb $(\mathrm{Pg} / \mathrm{ml})$ & $15.19 \pm 1.3$ & $10.48 \pm 0.5$ & $0.05^{*}$ \\
\hline Independent t-test. * ${ }^{*}$ $\leq 0.001$ (highly significant), ${ }^{*} \mathrm{p} \leq 0.05$ (significant). hsCRP: High-sensitive C-reactive \\
protein, AGP: Alpha-1-acid glycoprotein, TNF: Tumor necrosis factor.
\end{tabular}

Coefficient correlation between laboratory markers and anthropometric parameter showed significant negative correlation between EndoCAb (biomarker of microbial translocation) and weight and height $(p \leq 0.05)$. Zonulin (biomarker of enteric permeability) has significant negative correlation with weight $Z$ score and height $Z$ score $(p \leq 0.05)$. hsCRP (systemic acute phase reactant) has significant negative correlation with weight, WAZ, and arm circumference $(p \leq 0.05)$, and highly significant negative correlation with height and HAZ ( $p \leq 0.001)$. AGP (systemic acutephase reactant) has significant negative correlation with weight $Z$ score and height $Z$ score $(p \leq 0.05)$. TNF- $\alpha$ has no significant correlation of any of the anthropometric parameter $(p>0.05)$. On the other hand, Vitamin A has significant positive correlation with weight $Z$ score and BMI $Z$ score $(p \leq 0.05)$. Vitamin $D$ has significant positive correlation with weight $Z$ score and height $Z$ score $(p \leq 0.05)$, meanwhile, iron showed no significant correlation of any of the anthropometric parameter $(p>$ 0.05) (Table 3). 
Table 3: Correlation between anthropometric parameter and laboratory markers

\begin{tabular}{|c|c|c|c|c|c|c|c|c|}
\hline Variable & hs CRP (mg/l) & Zonulin (ng/ml) & AGP $(\mathrm{ng} / \mathrm{ml})$ & TNF (ng/L) & Vitamin A (Pg/ml) & EndoCAb (Pg/ml) & Vitamin D (Pg/ml) & Iron $(\mu \mathrm{g} / \mathrm{dl})$ \\
\hline \multicolumn{9}{|c|}{ Weight (kg) } \\
\hline $\mathrm{R}$ & $-0.473^{*}$ & -0.135 & -0.138 & -0.137 & -0.150 & $-0.276^{* *}$ & 0.117 & 0.023 \\
\hline $\mathrm{P}$ & 0.002 & 0.141 & 0.160 & 0.162 & 0.126 & 0.004 & 0.236 & 0.817 \\
\hline \multicolumn{9}{|c|}{ Weight $\mathrm{z}$ score } \\
\hline $\mathrm{R}$ & $-0.375^{\star}$ & $-0.412^{*}$ & $-0.279^{*}$ & 0.017 & $0.273^{\star}$ & -0.143 & $0.300^{\star \star}$ & -0.032 \\
\hline $\mathrm{P}$ & 0.008 & 0.002 & 0.004 & 0.863 & 0.005 & 0.144 & 0.002 & 0.749 \\
\hline \multicolumn{9}{|c|}{ Height $(\mathrm{cm})$} \\
\hline $\mathrm{R}$ & $-0.447^{\star *}$ & -0.127 & -0.109 & -0.089 & -0.181 & $-0.275^{\star}$ & 0.099 & -0.009 \\
\hline $\mathrm{P}$ & 0.000 & 0.273 & 0.269 & 0.368 & 0.064 & 0.004 & 0.313 & 0.929 \\
\hline \multicolumn{9}{|c|}{ Height $z$ score } \\
\hline $\mathrm{R}$ & $-0.385^{\star \star}$ & $-0.358^{*}$ & $-0.289^{*}$ & 0.098 & 0.065 & -0.177 & $0.237^{\star}$ & -0.133 \\
\hline $\mathrm{P}$ & 0.001 & 0.041 & 0.003 & 0.321 & 0.508 & 0.071 & 0.015 & 0.176 \\
\hline \multicolumn{9}{|l|}{ BMI } \\
\hline $\mathrm{R}$ & -0.172 & -0.182 & -0.144 & -0.159 & 0.134 & -0.118 & 0.105 & 0.042 \\
\hline $\mathrm{P}$ & 0.056 & 0.054 & 0.143 & 0.105 & 0.172 & 0.232 & 0.287 & 0.669 \\
\hline \multicolumn{9}{|c|}{ BMI z score } \\
\hline $\mathrm{R}$ & -0.037 & -0.162 & -0.076 & -0.124 & $0.201^{\star}$ & -0.084 & 0.021 & 0.020 \\
\hline $\mathrm{P}$ & 0.463 & 0.115 & 0.441 & 0.206 & 0.040 & 0.396 & 0.834 & 0.837 \\
\hline \multicolumn{9}{|c|}{ Arm circumference $(\mathrm{cm})$} \\
\hline $\mathrm{R}$ & $-0.395^{*}$ & -0.062 & -0.086 & -0.130 & -0.150 & -0.095 & 0.121 & -0.108 \\
\hline $\mathrm{P}$ & 0.050 & 0.713 & 0.384 & 0.187 & 0.126 & 0.334 & 0.218 & 0.272 \\
\hline
\end{tabular}

Logistic regression analysis for predicting factors for weight $Z$ score (at level $<-2$ ) revealed association with zonulin, $\alpha 1 \mathrm{AGP}$, and Vitamin $\mathrm{D}$. Its high lightened zonulin as the most significant predicator marker for weight $\mathrm{Z}$ score affection (adjusted odds ratio [AOR] 1.065; 95\% C.I.: 1.025, 1.060) (Table 4).

Table 4: Logistic regression analysis for factors affecting weight $Z$ score at level of $<-2$

\begin{tabular}{llllllll}
\hline Model & OR & S.E. & Wald & $p$ & AOR & \multicolumn{2}{c}{$95 \%$ C.I. for AOR } \\
\cline { 6 - 8 } & & & & & & Lower & Upper \\
\hline Zonulin & -0.031 & 0.009 & 12.947 & $0.000^{* *}$ & 1.065 & 1.025 & 1.060 \\
AGP & -0.049 & 0.020 & 5.937 & $0.015^{*}$ & 0.952 & 0.915 & 0.990 \\
Vitamin D & 0.118 & 0.035 & 11.425 & $0.001^{* *}$ & 1.125 & 1.051 & 1.204 \\
Iron & 0.025 & 0.003 & 2.934 & 0.143 & 0.737 & 0.711 & 0.756 \\
EndoCAb & -0.035 & 0.006 & 2.473 & 0.156 & 0.852 & 0.833 & 0.871 \\
Constant & -0.841 & 0.714 & 1.388 & 0.239 & 0.431 & & \\
\hline${ }^{* *} \leq 0.001$ (highly significant), ${ }^{*} p \leq 0.05$ (significant). AGP: Alpha-1-acid glycoprotein.
\end{tabular}

Meanwhile, linear stepwise regression analysis showed zonulin and $\alpha 1 \mathrm{AGP}$ as the most significant predicator marker for height $Z$ score affection (at level $<-2)([\mathrm{AOR}]$ 1.042; 95\% C.I.: 1.020, 1.065) ([AOR] 0.935; 95\% C.I.: 0.900, 0.970), respectively (Table 5).

Table 5: Logistic regression analysis for factors affecting height $Z$ score at level of $<-2$

\begin{tabular}{lccccccc}
\hline Model & OR & S.E. & Wald & $p$ & AOR & \multicolumn{2}{c}{ 95\% C.I. for AOR } \\
\cline { 6 - 8 } & & & & & & Lower & Upper \\
\hline Zonulin & -0.037 & 0.005 & 16.184 & $0.000^{* *}$ & 1.042 & 1.020 & 1.065 \\
AGP & -0.068 & 0.019 & 12.613 & $0.000^{* *}$ & 0.935 & 0.900 & 0.970 \\
Vitamin D & 0.053 & 0.028 & 3.768 & 0.052 & 1.055 & 0.999 & 1.113 \\
Iron & 0.0392 & 0.009 & 2.152 & 0.110 & 0.755 & 0.730 & 0.780 \\
EndoCAb & -0.043 & 0.017 & 2.376 & 0.098 & 0.843 & 0.821 & 0.860 \\
Constant & -1.674 & 0.659 & 6.447 & 0.011 & 0.187 & & \\
\hline${ }^{* *}$ p $\leq 0.001$ (highly significant) ${ }^{*} \mathrm{p} \leq 0.05$ (significant). AGP. & & &
\end{tabular}

\section{Discussion}

EED is subclinical chronic condition, often without gastrointestinal symptoms. It created a state of inefficient nutrients absorption and chronic longstanding inflammation which negatively worse EED and aggravates the condition. Causes and consequences are acting bidirectional in vicious circus pattern initiating and maintaining EED.
Malnutrition in young children has long terms comorbidities in old children and later adulthood. Stunting is impaired linear growth, it is defined as a height-forage $z$-score $\leq-2 \mathrm{SD}$ of the median height of the WHO reference population "wasting, is defined as reduction of the tissue mass $\leq-2$ SD of the mean in weight-forheight z scores [21]." Stunting usually presents in the early infancy period that may passed clinically neglected until late childhood. Untreated or impropriate nutrition may lead to permanent irreversible condition.

This case-control study enrolled 100 cases aged 1-10 years, suffering from malnutrition, and compared with 105 healthy children as controls. The mean age of our study group ranged between 6 and 7 years old, anthropometric measurements were highly significantly affected in cases group compared to controls group.

Several biomarkers have been carried out in EED diagnosis and prognosis. This study concerned with serum zonulin as indicator for intestinal permeability and absorption, serum EndoCAb as indicator for microbial translocation. Also, some serum markers for systemic inflammation as hsCRP, AGP, and TNF have been investigated.

Zonulin affects tight junctions between enterocytes producing increased intestinal permeability [5]. EndoCAb is antibody released against the LPS of Gram-negative bacteria [7].

This study revealed significant increase in serum zonulin and EndoCAb biomarkers in cases group more than the controls group.

Correlating the zonulin and EndoCAb in cases group with anthropometric parameters showed that both of them had significant negative correlation with weight $\mathrm{z}$ score and height $\mathrm{z}$ score, which is similar to the findings of Guerrant et al. [22] who found negative correlation between serum zonulin and stunting in a study done in Northeast Brazil on 375 child aged 6-26 months suffering from wasting or stunting. Meanwhile, logistic regression analysis in our study noted increase of zonulin as high associative markers with weight $Z$ score and height $Z$ score affection. 
Furthermore, in a study done by Uddin et al., 2021, the basic level of EndoCAb was assessed in children at 3 months of age with follow-up at 18 months, they found that the level of EndoCAb is elevated at the age of 3 months in the group of children who were subsequently underweight or stunted more than those who were well nourished. The same was similar to the finding of Campbell et al., 2003, who found EndoCAb correlated with growth retardation in the follow-up of the infants from 2 to 15 months on rural Gambian infants [23], [24].

In another study, EndoCAb has been assessed in multiplicity of diarrheal attacks and enteropathogenic infection as there was an association between serum EndoCAb antibodies with stunting at 1 year of age [25].

However, other results were not in line with ours, the increased EndoCAb was directly related with increased baseline HAZ [26]; no difference in EndoCAb levels was found in cases and controls groups that followed up in infancy period. Others [27] reported that EndoCAb titers were not correlated with measurements of growth HAZ or $\triangle H A Z$ (change of initial $H A Z$ from the time of assessment and times of follow-up) or intestinal permeability. Lin et al., 2013, notified that, however, EndoCAb titers in children from clean are lower than children from contaminated households, no strong association has found between EndoCAb and anthropometric measurements.

Overt diarrhea is not pathognomonic feature of EED. It has been associated with high variety and frequencies of infections even if not associated with clinical symptom of diarrhea [24], [28], [29]. EED may associated with subclinical infection which may be present apart from manifested diarrhea, however, other histopathological abnormalities and associated environmental and nutritional risk factors are present [30].

Regarding the systemic inflammatory biomarkers in this study, there was significant increase of serum hsCRP and AGP in cases group compared to controls group, however, TNF increased in cases group but with insignificant value. Correlating the systemic inflammatory biomarkers in cases group with anthropometric parameters revealed significant negative correlation between weight $Z$ score and both hsCRP and AGP. Furthermore, we detected significant negative correlation between height $Z$ score and hsCRP and AGP. Moreover, hsCRP showed highly significant negative correlation with height and significant negative correlation with weight and arm circumference. However, no significant correlations were found between TNF and anthropometric measurements. Our results were supported by the findings of Syed et al. [31], Iqbal et al. [32] where systemic inflammatory biomarkers, CRP and AGP, were positively correlated with stunting in Young Tanzanian Children that assessed at 6 weeks and 6 months.
In a study done on 202 Zimbabwean infants by Prendergast et al., 2014, the levels of CRP and AGP were consistently higher from 6 weeks to 12 months of age, which indicate that early inflammation at 6 weeks as measured by both AGP and CRP was associated with an increased risk of stunting. Furthermore, children who were stunted at 18 months of age had significantly high CRP and reduced insulin-like growth factor-1 which is a marker for linear growth [27].

Surveillance of CRP and AGP was clearly associated with decreasing LAZ score at 9 months of age. Meanwhile, CRP and AGP were both negatively correlated with IGF-1 at 6 and 9 months of age, which support the connection pathway between enteric biomarkers and systemic inflammatory markers with growth retardation [32].

A study ran on rural Ugandan infants based on established cutoffs values, about $46 \%$ of enrolled children had elevated AGP and about $30 \%$ had elevated CRP. Higher AGP and CRP concentrations were significantly associated with lower LAZ at 6 months of age but not WAZ or WLZ [33]. Similarly, study survey according to the cutoff point in 18 months aged infants revealed $56 \%$ having elevated AGP and $20 \%$ having elevated CRP [26], while others found that no significant correlations were noted with hsCRP levels and HAZ or WAZ at study start or with delta HAZ of impairing linear growth [22].

Tumor necrotic factor is pro-inflammatory cytokine that produced from $T$ lymphocytes, in EED, the ratio of TNF is increased in relation to other protective cytokines [3], [24]. It activates and drives differentiation of immune cells on infection [7]. It is one of the systemic inflammatory cytokines that detected with small intestine bacterial overgrowth in EED [34]. TNF has role and affects on the tight junction barrier between enterocytes in the gut, TNF pathological effect in the gut is known to be mediated by disruption of myosin light chain kinase which leading to affection of tight junction and gut permeability [35].

Limited data present about TNF assessment in EED or associative relations with the anthropometric parameters of growth were available. Meanwhile, this study showed no significant difference between cases and controls groups, or significant correlating relations with anthropometric measurements.

There is a logical comprehensive link between the implicated pathology in EED and intestinal absorption and bioavailability of essential micronutrients.

Vitamins $A$ and $D$ are belonging to fat-soluble group of vitamins. Vitamin A enhances gut mucosal lining and control permeability leading to defendant barrier against microbial infestation [36], [37]. In addition, it has a modulating role in $\mathrm{T}$ lymphocytes production, which plays a role controlling the chronic condition of EED. Moreover, Vitamin A deficiency may alter the intestinal microbiota which may compromise enteric pathogen 
clearance [38]. Vitamin D is involved in the processes of bone mineralization and growth through the regulation of calcium and phosphorus homeostasis [39]. The main site of Vitamins $A$ and $D$ absorption is small intestine which is the place of EED pathology [40].

Moreover, assessment of some micronutrients states revealed highly significant decrease of Vitamin $D$ in cases group ( $p \leq 0.001)$, in contrast to Vitamin A where no significant difference between the two groups was present $(p>0.05)$. Vitamin A showed significant positive correlation with weight $Z$ score and BMI Z score ( $p \leq 0.05)$. Likewise, Vitamin $D$ exhibited significant positive correlation with weight $Z$ score and height $Z$ score ( $p \leq 0.05$ ).

No significant statistical difference was found in this study throughout comparing the hemoglobin level between cases and controls groups. However, there was highly significant decrease of iron level in cases group ( $p \leq 0.001)$.

Applied interventional studies have shown that micronutrients, vitamins, and mineral supplementation improve intestinal morphology, reduce intestinal permeability, ameliorate gut functionality, and enhance linear growth [37].

Bacterial over growth and imbalance of the gut microbiota can both explain the state of subclinical infection and inflammatory markers imbalance that found in our studied cases group. It resulted in intestinal impermeability and elevated zonulin level and elevated antibodies against core bacteria (EndoCAb) creating a state of systemic inflammation denoted by elevated hsCRP and AGP, all that affect the absorptive function of the intestine affect the nutritional state that cleared in decreased Vitamin D micronutrient and manifested by affection of anthropometric parameters of weight and height.

\section{Conclusion}

Faltering growth is associated with elevated serum markers of Environmental enteric dysfunction such as biomarkers of enteric permeability (zonulin) and biomarkers of microbial translocation (EndoCAb), as well as biomarkers of systemic inflammation (HsCRP and AGP). EED may be a potential cause of faltering growth.

\section{Acknowledgment}

We are acknowledging the National Research Centre affiliation for funding our research. All appreciation to participants' children and their parents for their time and help. We are grateful to all researchers and their seniors for cooperation.

\section{References}

1. Tickell KD, Atlas HE, Walson JL. Environmental enteric dysfunction: A review of potential mechanisms, consequences and management strategies. BMC Med. 2019;17(1):181. https:// doi.org/10.1186/s12916-019-1417-3

PMid:31760941

2. Korpe PS, Petri WA. Environmental enteropathy: Critical implications of a poorly understood condition. Trends Mol Med. 2012;18(6):328-36. https://doi.org/10.1016/j. molmed.2012.04.007

PMid:22633998

3. Keusch GT, Denno DM, Black RE, Duggan C, Guerrant RL, Lavery JV, et al. Environmental enteric dysfunction: Pathogenesis, diagnosis, and clinical consequences. Clin Infect Dis. 2014;59 Suppl 4:S207-12. https://doi.org/10.1093/cid/ ciu485

PMid:25305288

4. Louis-Auguste J, Kelly P. Tropical enteropathies. Curr Gastroenterol Rep. 2017;19(7):29. https://doi.org/10.1007/ s11894-017-0570-0 PMid:28540669

5. de Morais MB, da Silva GA. Environmental enteric dysfunction and growth. J Pediatr (Rio J). 2019;95 Suppl 1:85-94. https:// doi.org/10.1016/j.jped.2018.11.004

PMid:30629923

6. Syed S, Ali A, Duggan C. Environmental enteric dysfunction in children: A review HHS public access. J Pediatr Gastroenterol Nutr. 2016;63(1):6-14. https://doi.org/10.1097/ MPG.0000000000001147

PMid:26974416

7. El Wakeel MA, El-Kassas GM, Ahmed GF, Ali WH, Elsheikh EM, El-Zayat SR, et al. Fecal markers of environmental enteric dysfunction and their relation to faltering growth in a sample of Egyptian children. Open Access Maced J Med Sci. 2021;9(B):1117-22. https://doi.org/10.3889/oamjms.2021.7029.

8. Crane RJ, Jones KDJ, Berkley JA. Environmental enteric dysfunction:Anoverview. Food Nutr Bull. 2015;36 Suppl 1:S76-87. https://doi.org/10.1177/15648265150361S113 PMid:25902619

9. Ali A, Iqbal NT, Sadiq K. Environmental enteropathy. Curr Opin Gastroenterol. 2016;32(1):12-7. https://doi.org/10.1097/ MOG.0000000000000226

PMid:26574871

10. Lee GO, Olortegui MP, Salas MS, Yori PP, Trigoso DR, Kosek $\mathrm{P}$, et al. Environmental enteropathy is associated with cardiometabolic risk factors in Peruvian children. J Dev Orig Health Dis. 2017;8(3):337-48. https://doi.org/10.1017/ S2040174417000071

PMid:28264759

11. Ashaat EA, Taman KH, Kholoussi N, El Ruby MO, Zaki ME, E Wakeel MA, et al. Altered adaptive cellular immune function in a group of Egyptian children with autism. J Clin Diagn Res. 2017;11(10):1-4. https://doi.org/10.7860/jcdr/2017/28124.1078.

12. Elzaree FA, Shehata MA, EI Wakeel MA, El-Alameey IR, Abushady MM, Helal SI. Adaptive functioning and psychosocial problems in children with beta thalassemia major. Open Access Maced J Med Sci. 2018;6(12):2337-41. https://doi.org/10.3889/ oamjms.2018.367

PMid:30607187

13. Oriá RB, Murray-Kolb LE, Scharf RJ, Pendergast LL, Lang DR, Kolling GL, et al. Early-life enteric infections: Relation between chronic systemic inflammation and poor cognition in children. Nutr Rev. 2016;74(6):374-86. https://doi.org/10.1093/nutrit/ 
nuw008

PMid:27142301

14. Thompson AJ, Hughes M, Anastasova S, Conklin LS, Thomas T, Leggett $\mathrm{C}$, et al. The potential role of optical biopsy in the study and diagnosis of environmental enteric dysfunction. Nat Rev Gastroenterol Hepatol. 2017;14(12):727-38. https://doi. org/10.1038/nrgastro.2017.147

15. El-Wakeel MA, El-Kassas GM, Fathy GA, El Wakkad AS Sebaii HM, El Zayat SM, et al. Diagnostic and prognostic values of high sensitive C- reactive protein, tumor necrosis factor and interleukin-1 $\beta$ in neonatal sepsis. Aust J Basic Appl Sci. 2012;6(3):224-8.

16. Fasano A. All disease begins in the (leaky) gut: Role of zonulinmediated gut permeability in the pathogenesis of some chronic inflammatory diseases. F1000Res. 2020;9:F1000. https://doi. org/10.12688/f1000research.20510.1

PMid:32051759

17. Martorell TG. Anthropometric Standardization Reference Manual. Champaign, IL: Human Kinetics Books; 1988. Available from:https://www.worldcat.org/title/anthropometricstandardization-reference-manual/oclc/15592588. [Last accessed on 2021 May 23].

18. Tanner JM, Hiernaux J, Jarman S, Weiner JS, Lourie JA. Growth, and physique studies. In: Weiner JS, Lourie SA, editors. Human Biology: A Guidance to Fields Methods. London: Blackwell Scientific Publications; 1969. p. 273-5.

19. WHO. WHO Anthro Plus for Personal Computers. Manual Software for Assessing Growth of the World's Children and Adolescents. (Version 3.2. 2, January 2011) and Macros. Geneva: WHO; 2011. Available from: http://www.who.int/ childgrowth/software/en. [Last accessed on 2021 Jun 12].

20. World Health Organization. WHO Child Growth Standards: Head Circumference-for-Age, Arm Circumference-for-Age, Triceps Skinfold-for-Age and Subscapular Skinfold-for-Age: Methods and Development. Vol. 46. United States: American Journal of Clinical Nutrition; 2007. Available from: http://www. who.int/childgrowth/standards/second_set/technical_report_2. pdf. [Last accessed on 2017 Apr 03].

21. de Onis $\mathrm{M}$. WHO child growth standards based on length/height, weight and age. Acta Paediatr Int J Paediatr. 2006;95 Suppl 450:76-85.

22. Guerrant RL, Leite $A M$, Pinkerton $R$, Medeiros $P H$, Cavalcante PA, Deboer M, et al. Biomarkers of environmental enteropathy, inflammation, stunting, and impaired growth in children in northeast Brazil. PLoS One. 2016;11(9):e0158772. https://doi.org/10.1371/journal.pone.0158772

PMid:27690129

23. Uddin MI, Hossain M, Islam S, Akter A, Nishat NS, Nila TA, et al. An assessment of potential biomarkers of environment enteropathy and its association with age and microbial infections among children in Bangladesh. PLoS One. 2021;16(4):e0250446. https://doi.org/10.1371/journal.pone.0250446 PMid:33886672

24. Campbell DI, Elia M, Lunn PG. Growth faltering in rural Gambian infants is associated with impaired small intestinal barrier function, leading to endotoxemia and systemic inflammation. J Nutr. 2003;133(5):1332-8. https://doi.org/10.1093/ jn/133.5.1332

PMid: 12730419

25. Taniuchi M, Sobuz SU, Begum S, Platts-Mills JA, Liu J, Yang Z, et al. Etiology of diarrhea in bangladeshi infants in the first year of life analyzed using molecular methods. J Infect Dis. 2013;208(11):1794-802. https://doi.org/10.1093/infdis/jit507 PMid:24041797

26. Campbell RK, Schulze KJ, Shaikh S, Mehra S, Ali H, $\mathrm{Wu} \mathrm{L}$, et al. Biomarkers of environmental enteric dysfunction among children in rural Bangladesh. J Pediatr Gastroenterol Nutr. 2017;65(1):40-6. https://doi.org/10.1097/ MPG.0000000000001557

PMid:28644348

27. Prendergast AJ, Rukobo S, Chasekwa B, Mutasa K, Ntozini R, Mbuya MN, et al. Stunting is characterized by chronic inflammation in zimbabwean infants. PLoS One. 2014;9(2):e86928. https://doi. org/10.1371/journal.pone.0086928 PMid:24558364

28. Lin A, Arnold B, Afreen S, Goto R, Huda T, Haque R, et al. Household environmental conditions are associated with enteropathy and impaired growth in rural Bangladesh. Am J Trop Med Hyg. 2013;89(1):130-7. https://doi.org/10.4269/ ajtmh.12-0629

PMid:23629931

29. Lunn PG, Northrop-Clewes CA, Downes RM. Intestinal permeability, mucosal injury, and growth faltering in Gambian infants. Lancet. 1991;338(8772):907-10. https://doi. org/10.1016/0140-6736(91)91772-m

PMid:1681266

30. Millward DJ. Nutrition, infection and stunting: The roles of deficiencies of individual nutrients and foods, and of inflammation, as determinants of reduced linear growth of children. Nutr Res Rev. 2017;30(1):50-72. https://doi. org/10.1017/S0954422416000238

PMid:28112064

31. Syed S, Manji KP, Mcdonald CM, Kisenge R, Aboud S, Sudfeld $\mathrm{C}$, et al. Biomarkers of systemic inflammation and growth in early infancy are associated with stunting in young Tanzanian children. Nutrients. 2018;10(9):1158. https://doi. org/10.3390/nu10091158

PMid:30149537

32. Iqbal NT, Sadiq K, Syed S, Akhund T, Umrani F, Ahmed S, et al. Promising biomarkers of environmental enteric dysfunction: A prospective cohort study in. Sci Rep. 2018;8(1):2966. https:// doi.org/10.1038/s41598-018-21319-8 PMid:29445110

33. Lauer JM, Ghosh S, Ausman LM, Webb P, Bashaasha B, Agaba $\mathrm{E}$, et al. Markers of environmental enteric dysfunction are associated with poor growth and iron status in rural ugandan infants. J Nutr. 2020;150(8):2175-82. https://doi.org/10.1093/jn/ nxaa141

\section{PMid:32455424}

34. Donowitz JR, Haque R, Kirkpatrick BD, Alam M, Lu M, Kabir $\mathrm{M}$, et al. Small intestine bacterial overgrowth and environmental enteropathy in Bangladeshi children. MBio. 2016;7(1):e02102-15. https://doi.org/10.1128/mBio.02102-15 PMid:26758185

35. Sturgeon C, Fasano A. Zonulin, a regulator of epithelial and endothelial barrier functions, and its involvement in chronic inflammatory diseases. Tissue Barriers. 2016;4(4):e1251384. https://doi.org/10.1080/21688370.2016.1251384

PMid:28123927

36. Thurnham DI, Northrop-Clewes CA, Mc Cullough FS, Das BS, Lunn PG. Innate immunity, gut integrity, and Vitamin A in Gambian and Indian infants. J Infect Dis. 2000;182(3):S23-8. https://doi.org/10.1086/315912

PMid:10944481

37. Loechl C. Technical meeting on environmental enteric dysfunction, microbiome and undernutrition. IAEA Nutr Health Environ Stud Sect. 2015;43(1):1-6.

38. de Medeiros PH, Pinto DV, de Almeida JZ, Rêgo JM, Rodrigues FA, Lima AÂ, et al. Modulation of intestinal immune and barrier functions by Vitamin A: Implications for current understanding of malnutrition and enteric infections in children. 
Nutrients. 2018;10(9):1128. https://doi.org/10.3390/nu10091128 PMid:30134532

39. Taylor SN. Vitamin D in toddlers, preschool children, and adolescents. Ann Nutr Metab. 2020;76 Suppl 2:30-41. https:// doi.org/10.1159/000505635
PMid:33232959

40. El-Shaheed AA, El-Arab AE, El-Kassas GM, El Wakeel MA, Abou-Zekri M, El-Banna M. An innovative effective nutritional therapy for Vitamin $D$ deficiency in children with celiac disease. Biomed Pharmacol J. 2019;12(3):1481-90. 